\title{
Peripheral optical coherence tomography assisted by scleral depression in retinopathy of prematurity
}

Brittni A. Scruggs, MD, $\mathrm{PhD}^{1}$, Shuibin Ni, MS ${ }^{1}$, Thanh-Tin P. Nguyen, MD ${ }^{1}$, Susan Ostmo, $\mathrm{MS}^{1}$, Michael F. Chiang, MD², Yali Jia, $\mathrm{PhD}^{1}$, David Huang, MD, PhD ${ }^{1}$, Yifan Jian, $\mathrm{PhD}^{1, *}, \mathrm{~J}^{*}$ Peter Campbell, MD, MPH ${ }^{1, *}$

${ }^{1}$ Casey Eye Institute, Department of Ophthalmology, Oregon Health \& Science University, Portland, OR, USA

${ }^{2}$ National Eye Institute, National Institutes of Health, Bethesda, MD, USA

*Corresponding author

\section{Corresponding Author:}

\section{J. Peter Campbell, MD, MPH}

Department of Ophthalmology, Casey Eye Institute, Oregon Health \& Science University, 515 SW Campus Dr, Portland, OR, 97239

Fax: 503-494-7233

Email: campbelp@ohsu.edu

*Dr. Jian and Dr. Campbell supervised this work equally

\section{Financial Support:}

This work was supported by grants R01 EY19474, R01 EY031331, R21 EY031883, and P30 EY10572 from the National Institutes of Health (Bethesda, MD), and by unrestricted departmental funding and a Career Development Award (JPC) and a Career Advancement Award (YJ) from Research to Prevent Blindness (New York, NY).

\section{Financial Disclosures:}

J. Peter Campbell receives research support from Genentech and is a consultant to Boston AI labs. Yifan Jian has financial interests in Seymour Vision. Oregon Health \& Science University (OHSU) and Yali Jia have a significant financial interest in Optos, Inc. OHSU, Yali Jia, and David Huang have a significant financial interest in Optovue, Inc. These potential conflicts of interest have been reviewed and managed by OHSU. Other authors declare that there are no conflicts of interest related to this article.

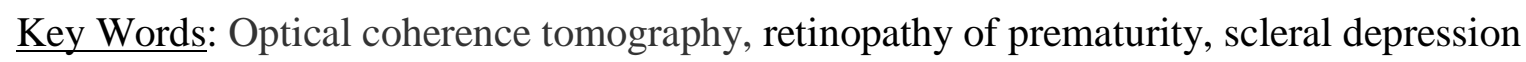




\section{ABSTRACT}

Objective: To determine whether handheld widefield optical coherence tomography (OCT) can

44 be used to document retinopathy of prematurity (ROP) stage while using scleral depression to

45 improve peripheral views.

Design: Prospective observational study

Participants: Consecutive neonates admitted to the neonatal intensive care unit (NICU) in a single academic medical center who also met criteria for ROP screening and consented for research imaging.

Methods: Scleral depression was combined with widefield OCT using an investigational 400$\mathrm{kHz}, 55$-degree field of view handheld OCT during ROP screening from October 28, 2020 to March 03, 2021.

Main Outcome Measures: Acquisition of en face and B-scan imaging of the peripheral retina to objectively assess early vitreoretinal pathology, including the demarcation between vascularized and anterior avascular retina, the presence of early ridge formation, and small neovascular tufts.

Results: Various stages of ROP were detected using a rapid acquisition OCT system. In one neonate, serial OCT imaging over a five-week period demonstrated accumulation of neovascular tufts with progression to stage 3 ROP with extraretinal fibrovascular proliferation along the ridge. Videography of this technique is included in this report for instructional purposes. detection and documentation of ROP disease progression. Earlier detection of ROP-related 
medRxiv preprint doi: https://doi.org/10.1101/2021.10.14.21265026; this version posted October 17, 2021. The copyright holder for this preprint (which was not certified by peer review) is the author/funder, who has granted medRxiv a license to display the preprint in perpetuity.

All rights reserved. No reuse allowed without permission.

\section{INTRODUCTION}

82

83

84

85

86

87

88

89

The routine use of optical coherence tomography (OCT) in retinopathy of prematurity (ROP) has been limited, despite the advantages OCT provides in the care of patients with retinal diseases. In adults, the leading causes of blindness include age-related macular degeneration and diabetic retinopathy; in both, OCT is more sensitive than the clinical exam for detection of severe disease, and it has become standard of care and facilitated the transition towards quantitative and objective disease screening, diagnosis, and monitoring. This has resulted in opportunities for earlier treatment and improved visual outcomes.

In ROP, the standard of care remains the ophthalmoscopic exam, with subjective assessment of zone, stage, and plus disease. Prior applications of OCT in ROP have been limited by the field of view (FOV) of the commercially available and investigational OCT systems. Thus, most early applications of OCT have focused on posterior manifestations of ROP, rather than assessment of peripheral ROP stage. ${ }^{1-7}$ Previous work has demonstrated that OCT may provide added information about foveal architecture, ${ }^{2}$ vitreous organization, ${ }^{6}$ three dimensional manifestations of plus disease, ${ }^{7}$ and other clinical signs that we cannot appreciate using the clinical exam. In addition, Mangalesh, et al. recently demonstrated the potential for reduced neonatal stress using OCT rather than the clinical exam, which is a key potential benefit of screening with OCT. ${ }^{1}$

Unlike in most applications of OCT, the primary pathology in ROP is peripheral; therefore, the most compelling case would be made if OCT could reliably diagnose the stage of disease, potentially replacing the ophthalmoscopic examination. Several groups have demonstrated investigational OCT devices can achieve wider fields of view, roughly equivalent to the visualization provided by indirect ophthalmoscopy; however, these still cannot routinely 
105 visualize the retinal periphery. ${ }^{3,8}$ Given that clinical assessment of peripheral ROP with

106 ophthalmoscopy often requires scleral depression, we tested in this study the hypothesis that

107 scleral depression, combined with the use of a widefield OCT system, could provide accurate,

108 objective, and rapid assessment of ROP stage.

\section{METHODS}

111 Handheld OCT retinal imaging was performed on fully awake neonates in the neonatal intensive

112 care unit (NICU) at Oregon Health \& Science University (OHSU) during the period of October

11328,2020 to March 03, 2021. Infants were included in the study if they met eligibility criteria for

114 ROP screening (birth weight $\leq 1500 \mathrm{~g}$ and/or a gestational age $\leq 30$ weeks), and if parent(s)

115 consented for research imaging. Any infant whose parent(s) declined participation in the study

116 were excluded and did not undergo research imaging; however, those infants still underwent

117 ROP screening using traditional methods, including indirect ophthalmoscopy. Thirteen infants

118 were included in this study, and the research OCT images were obtained at each visit during

119 usual ROP screening. Birthweight, gestational age, gender, race/ethnicity, ROP zone by clinical

120 assessment, and ROP stage by clinical assessment were recorded for all infants (Table 1). The

121 imaging for the non-sedated infants was conducted with pharmacological dilation with

122 cyclopentolate $0.2 \%$ and phenylephrine $1 \%$. After installation of anesthetic eye drops, an infant

123 lid speculum was utilized, scleral depression was performed in a manner similar to the clinical

124 ROP examination. This study was approved by the Institutional Review Board/Ethics Committee

125 of OHSU in accordance with the Declaration of Helsinki.

127 this study. ${ }^{9}$ This portable handheld OCT extends views to the peripheral retina of pediatric 
128 patients and displays cross-sectional (i.e., B-scan) and en face views in real time. ${ }^{10}$ With a

129 single hand, the operator could hold the lens tube, allowing the operator to rest parts of their

130 palm gently on the infant's forehead and to manipulate the eye position using a depressor with

131 their other hand (Video 1). The acquisition time of each volume was $120 \mathrm{~ms}$ with $400 \mathrm{~A}$-scan

132 per B-scan and 120 B-scans per volume, which provided real-time feedback in optimizing

133 images. Once the target area on the ocular fundus was located, autofocusing with

134 an electronically focus tunable lens could be performed in 1 second based on the brightness of

135 the en face view.

136 The OCT images were reviewed in real-time by the examiners (S.O., Y.J., and J.P.C.),

137 and additional images were taken, when needed, to obtain good quality images of the retinal

138 periphery for each infant, except when clinical needs of the baby superseded the value of

139 obtaining research imaging. OCT images were obtained of the temporal, posterior, and nasal

140 retina at every session, as well as the superior and inferior when relevant pathology was

141 suspected or noted. The ROP zone and stage associated with any OCT image were determined

142 by the examiner using traditional examination with indirect ophthalmoscopy. RetCam imaging

143 was performed in select cases to document clinical findings.

\section{$145 \quad$ RESULTS}

146 In this study, 13 awake neonates in the NICU were imaged during routine ROP screening with

147 serial imaging during the study period when possible. Imaging was obtained in nearly every

148 eligible patient, excepting those whose clinical instability prevented the acquisition of research

149 images (fewer than 3 babies during study period). In total, forty clinical visits were completed,

150 and OCT images were obtained at each session to view the retinal periphery of each infant. 
medRxiv preprint doi: https://doi.org/10.1101/2021.10.14.21265026; this version posted October 17, 2021. The copyright holder for this preprint (which was not certified by peer review) is the author/funder, who has granted medRxiv a license to display the preprint in perpetuity.

All rights reserved. No reuse allowed without permission.

151 Using the en face OCT view of the periphery with scleral depression, the extent of

152 vascularization (zone) and any vascular abnormalities (stage) could be determined, as shown in

153 Figure 1 and Video 2. In eyes that were fully vascularized, the scleral depressor could be

154 visualized with retinal vessels extending within one disc area of the ora serrata (Video 1). In

155 contrast, in eyes that demonstrated persistent avascular retina, or any degree of stage, the edge of

156 the vascularized retina could be viewed en face (Figure 1 \& Video 2).

We observed a spectrum of vascular abnormalities ranging from avascular retina without

158 a clear demarcation line (sometimes referred to as stage 0; Fig 1A), to extraretinal

159 neovascularization (stage 3; Fig 1F). Even when comparing two neonates with clinical stage 1

160 ROP (Fig 1 B-C), there were meaningful differences in OCT appearance, including B-scan

161 images. Fig 1B shows a faint demarcation line separating the vascularized and anterior avascular

162 retina without dimension, whereas Fig. 1C shows a more distinct demarcation line. Similarly, the

163 images in Fig 1 D-E show early stage 2 ROP (Fig 1D) compared to the prominent, more

164 vascularized later stage 2 ROP (Fig 1E).

This technique can also be used to monitor the progression of ROP over time. Figure 2

166 and Video 3 show OCT en face images of the posterior pole and peripheral retina obtained with

167 B-scan images of the peripheral pathology in one neonate over a five-week period. This one

168 example demonstrates two important concepts. First, while the anterior ridge slowly progressed

169 into a typical stage 3 lesion by week 5, the serial OCT imaging demonstrated accumulation of

170 "popcorn" neovascular tufts (typically associated with stage 2 ROP) with clear and continuous

171 progression of extraretinal fibrovascular proliferation along the ridge in the weeks prior. Second,

172 the en face images centered on the posterior pole showed increased vascular dilation and

173 tortuosity over time, correlating with the increased severity of peripheral disease. 


\section{DISCUSSION}

In this report, we demonstrate that the peripheral ROP stage can be documented with

177 OCT using scleral depression and that stage appears to represent a spectrum from avascular

178 retina to extraretinal neovascularization. Zone III is clearly visualized using technique, and these

179 far peripheral views provide objective documentation of the extent of vascularization and/or

180 avascular retina for preterm infants. This study also suggests that changes in the posterior pole in

181 the spectrum of pre-plus and plus disease correspond to the degree and progression of stage, as

182 has been seen with artificial intelligence-based assessment of vascular severity, but further work

183 is needed to establish the relationship via OCT. ${ }^{11}$

184 Videography of this entire process has been provided to demonstrate the utility of this

185 imaging modality at bedside with minimal disruption to the neonate or ROP screening process.

186 We have found that incorporating OCT in our practice, especially when performed with scleral

187 depression, improves our ability to visualize peripheral ROP, to teach trainees, to communicate

188 findings with NICU staff and parents, and to visualize early vitreoretinal traction not visible with 189 ophthalmoscopy.

Using the en face real-time viewing, OCT can be used as an ophthalmoscope. In addition

191 to visualizing the vasculature, OCT can objectively assess the degree of vascular abnormalities.

192 Chen, et al previously demonstrated OCT examples at the vascular-avascular junction with

193 comparison to prior histology. ${ }^{3}$ In this report, we demonstrate that with scleral depression it may

194 be feasible to utilize OCT in ROP practice, overcoming one of the limitations to its use.

195 Although in this series we did not observe any retinal detachments, an added advantage of using

196 OCT to detect extraretinal fibrovascular tissue is that it may be more sensitive for detection of 
medRxiv preprint doi: https://doi.org/10.1101/2021.10.14.21265026; this version posted October 17, 2021. The copyright holder for this preprint (which was not certified by peer review) is the author/funder, who has granted medRxiv a license to display the preprint in perpetuity.

All rights reserved. No reuse allowed without permission.

197 "flat" extraretinal neovascularization associated with aggressive ROP (AROP) and earlier signs

198 of vitreoretinal traction, which can be very difficult to appreciate clinically.

199

\section{CONCLUSION}

201 In this study, the combination of widefield OCT and scleral depression allow detection and

202 documentation of ROP stage and progression of peripheral pathology. As the cost of this

203 technology comes down, we hope that reports like this demonstrating added clinical value may

204 lead to routine use of OCT as part of ROP screening, earlier detection of progressive stage and

205 extent of disease, fewer retinal detachments, and improved visual outcomes in ROP. 
medRxiv preprint doi: https://doi.org/10.1101/2021.10.14.21265026; this version posted October 17, 2021. The copyright holder for this preprint (which was not certified by peer review) is the author/funder, who has granted medRxiv a license to display the preprint in perpetuity.

All rights reserved. No reuse allowed without permission.

\section{REFERENCES:}

207 1. Mangalesh S, Sarin N, McGeehan B, et al. Preterm Infant Stress During Handheld

208 Optical Coherence Tomography vs Binocular Indirect Ophthalmoscopy Examination for

209 Retinopathy of Prematurity. JAMA Ophthalmol. Apr

$210 \quad 2021 ;$ doi:10.1001/jamaophthalmol.2021.0377

$2112 . \quad$ Vinekar A, Mangalesh S, Jayadev C, Maldonado RS, Bauer N, Toth CA. Retinal Imaging

212 of Infants on Spectral Domain Optical Coherence Tomography. Biomed Res Int.

$213 \quad 2015 ; 2015: 782420$. doi:10.1155/2015/782420

$2143 . \quad$ Chen X, Mangalesh S, Dandridge A, et al. Spectral-Domain OCT Findings of Retinal

215 Vascular-Avascular Junction in Infants with Retinopathy of Prematurity. Ophthalmol Retina. Sep

216 2018;2(9):963-971. doi:10.1016/j.oret.2018.02.001

217 4. Mangalesh S, McGeehan B, Tai V, et al. Macular OCT Characteristics at 36 Weeks'

218 Postmenstrual Age in Infants Examined for Retinopathy of Prematurity. Ophthalmol Retina. Sep

219 2020;doi:10.1016/j.oret.2020.09.004

220 5. Rothman AL, Tran-Viet D, Gustafson KE, et al. Poorer neurodevelopmental outcomes

221

222

223

224

225

226

227

228

229

230

231

232

233

234

235

236

237

238

239

240

241

242 associated with cystoid macular edema identified in preterm infants in the intensive care nursery. Ophthalmology. Mar 2015;122(3):610-9. doi:10.1016/j.ophtha.2014.09.022

6. Legocki AT, Zepeda EM, Gillette TB, et al. Vitreous Findings by Handheld SpectralDomain OCT Correlate with Retinopathy of Prematurity Severity. Ophthalmol Retina. 10 2020;4(10):1008-1015. doi:10.1016/j.oret.2020.03.027

7. Maldonado RS, Yuan E, Tran-Viet D, et al. Three-dimensional assessment of vascular and perivascular characteristics in subjects with retinopathy of prematurity. Ophthalmology. Jun 2014;121(6):1289-96. doi:10.1016/j.ophtha.2013.12.004

8. Campbell JP, Nudleman E, Yang J, et al. Handheld Optical Coherence Tomography Angiography and Ultra-Wide-Field Optical Coherence Tomography in Retinopathy of Prematurity. JAMA Ophthalmol. 09 2017;135(9):977-981. doi:10.1001/jamaophthalmol.2017.2481

9. $\quad \mathrm{Ni} \mathrm{S}$, Wei X, Ng R, et al. High-speed and widefield handheld swept-source OCT angiography with a VCSEL light source. Biomed Opt Express. Jun 01 2021;12(6):3553-3570. doi:10.1364/BOE.425411

10. Jian Y, Wong K, Sarunic MV. Graphics processing unit accelerated optical coherence tomography processing at megahertz axial scan rate and high resolution video rate volumetric rendering. J Biomed Opt. Feb 2013;18(2):26002. doi:10.1117/1.JBO.18.2.026002

11. Campbell JP, Kim SJ, Brown JM, et al. Evaluation of a Deep Learning-Derived Quantitative Retinopathy of Prematurity Severity Scale. Ophthalmology. Oct 2020;doi:10.1016/j.ophtha.2020.10.025 
medRxiv preprint doi: https://doi.org/10.1101/2021.10.14.21265026; this version posted October 17, 2021. The copyright holder for this preprint (which was not certified by peer review) is the author/funder, who has granted medRxiv a license to display the preprint in perpetuity.

All rights reserved. No reuse allowed without permission.

\section{Figure Legends:}

245 Figure 1. ROP peripheral pathology as seen with peripheral OCT en face and cross-sectional

246 imaging using scleral depression. A, Avascular retina without clear vascular-avascular border

247 (sometimes referred to as stage 0 ROP). B-C, Two examples of stage 1 ROP visible with faint

248 (B) and more pronounced (C) demarcation lines without ridge formation. The asterisk indicates

249 scleral depressor location. D-E, Two examples of stage 2 ROP with early (D) and later (E) ridge

250 formation without neovascularization. F, Stage 3 ROP with significant extraretinal fibrovascular

251 proliferation along the ridge. The yellow vertical lines correlate to the upper cross-sectional

252 images; yellow horizontal lines correlate to lower cross-sectional images.

254 Figure 2. Monitoring ROP disease progression in a preterm infant using OCT en face and cross-

255 sectional views. Top row: Posterior en face views over a five-week period demonstrate

256 increased vascular tortuosity. Second row: Serial peripheral en face views centered on the

257 patient's peripheral ridge show increased severity of ROP disease over time. The yellow

258 horizontal lines correlate to the respective cross-sectional images obtained posterior to the ridge

259 (Third row, top image). The yellow vertical lines correlate to the respective cross-sectional

260 images obtained across the ridge (Third row, bottom image). 
medRxiv preprint doi: https://doi.org/10.1101/2021.10.14.21265026; this version posted October 17, 2021. The copyright holder for this preprint (which was not certified by peer review) is the author/funder, who has granted medRxiv a license to display the preprint in perpetuity.

All rights reserved. No reuse allowed without permission.

\section{Video Legends:}

264 Video 1. Visualization of the peripheral retina during ROP screening using scleral depression

265 and OCT. En face views and cross-sectional scans are shown simultaneously in real time. The

266 scleral depressor, seen prior to image acquisition, provides indentation throughout this process

267 and facilitates view of peripheral vasculature. This video demonstrates the rapid acquisition time

268 of the investigational portable handheld OCT system.

270 Video 2. Documentation of various ROP stages detected by OCT using scleral depression. This

271 video shows real time acquisition of OCT en face and cross-sectional scans of five preterm

272 infants. The images are shown in increasing severity of ROP peripheral pathology. The

273 videography clips of Patients 1-5 correspond with the images in Fig 1 B-F, respectively. Patients

2741 and 2 demonstrate examples of stage 1 ROP, whereas patients 3 and 4 had clinical evidence of

275 stage 2 ROP. Patient 5 had extraretinal fibrovascular proliferation, consistent with stage 3 ROP.

276

277 Video 3. OCT detection of peripheral ROP disease progression. OCT en face views centered on

278 a patient's peripheral ridge demonstrate increased severity of ROP disease over a five-week

279 period. The adjacent cross-sectional images demonstrate an increase in "popcorn"

280 neovascularization tufts and extraretinal fibrovascular tissue over this period. By week 5, the

281 patient had evidence of stage $3 \mathrm{ROP}$ and underwent treatment. 


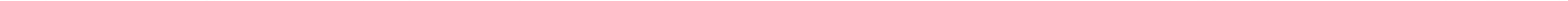




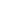

